\title{
Potencialidades do processo de implementação de Unidades Didáticas Multiestratégicas para a formação inicial de professores de Química
}

\author{
Potentialities of the implementation process of Multi-Strategic Didactic Units for \\ chemistry teacher education
}

\author{
Francisco Otávio Cintra Ferrarini ${ }^{1}$ \\ Amadeu Moura Bego ${ }^{2}$
}

\section{Resumo}

Este artigo pretende expor considerações relativas à importância do movimento de reflexão crítica acerca da ação do replanejamento de Unidades Didáticas Multiestratégicas (UDM) de professores de Química em formação inicial. Trata-se de um recorte de uma pesquisa de doutorado que envolveu a utilização e validação de categorias a priori para se avaliar o Enfoque Curricular adotado por futuros professores ao planejarem e replanejarem UDM. Foi utilizada a abordagem de pesquisa qualitativa do tipo Estudo de Caso para se caracterizarem eventuais mudanças empreendidas na proposição do planejamento de ensino. Para isso foram consideradas como categorias analíticas o Conteúdo abordado, a Metodologia escolhida e as considerações acerca da Avaliação na composição do replanejamento. Os dados gerados apresentam potencialidade de explicitar e caracterizar as reflexões críticas empreendidas em planejamentos de ensino, bem como capacidade de estipular posicionamentos transitórios e direcionados à consolidação de tendências alternativas com referencial investigativo. Isso se deve ao fato de os sujeitos desta pesquisa terem se mobilizado diante de uma proposta que pretendia promover transições e evoluções de conhecimentos profissionais, além de fundamentar a constituição de um modelo didático pessoal capaz de se descolar de perspectivas tradicionais.

Palavras-chave: Planejamento de ensino. Ensino de Química. Inovação educacional.

\begin{abstract}
This article intends to expose considerations regarding the importance of the critical reflection movement about the action of the replanning of Multi-Strategic Didactic Units (UDM) of Chemistry teachers in initial training. This is an excerpt from a doctoral research that involved the use and validation of categories a priori to evaluate the Curricular

\footnotetext{
${ }^{1}$ Licenciado em Química. Mestre em Química Inorgânica. Doutor em Ensino de Química pelo Instituto de Química da Universidade Estadual Paulista (Unesp), Campus de Araraquara, SP. Atualmente é Professor do IFSP - Campus Matão. E-mail: franciscoferrarini@ifsp.edu.br

2 Professor Assistente Doutor junto ao Departamento de Química Geral e Inorgânica do Instituto de Química da Unesp, Campus Araraquara, SP. Atua também como Coordenador do Programa de Mestrado Profissional em Química em Rede (PROFQUI-Araraquara). E-mail: amadeu.bego@unesp.br
} 


\section{-Revista de Iniciação à Docência, v.6, n.2, 2021- \\ Publicação: dezembro, 2021 - ISSN 2525-4332}

Approach adopted by future teachers when planning and replanning UDM. The case study qualitative research approach was used to characterize eventual changes undertaken in the teaching planning proposal. For that, the content covered, the chosen Methodology and the considerations about the Evaluation in the composition of the replanning were considered as analytical categories. The data generated have the potential to make explicit and characterize the critical reflections undertaken in teaching plans, as well as the ability to stipulate transient positions aimed at consolidating alternative trends with an investigative framework. This is due to the fact that the subjects of this research were mobilized in the face of a proposal that intended to promote transitions and evolutions of professional knowledge, in addition to supporting the constitution of a personal didactic model capable of detaching from traditional perspectives.

Keywords: Lesson planning. Chemistry teaching. Educational innovation.

\section{Introdução}

No geral, os planejamentos de ensino de professores têm sido caracterizados como atividades meramente burocráticas e descontextualizadas da realidade escolar. Pesquisas têm revelado as seguintes características predominantes no que se refere ao planejamento docente: centralização na seleção do conteúdo conceitual da disciplina para as atividades de ensino; adoção e limitação a um único livro didático para seleção e sequenciamento do conteúdo; crença em um ensino estritamente teórico (ALVES, 2018; FERRARINI, 2020; GAUCHE, 2015; PACCA; SCARINCI, 2013; SANCHEZ; VALCÁRCEL, 2000).

A despeito dessas tendências e intentando pautar sua importância central para ações de inovação, Bego (2016) propõe um modelo de planejamento de ensino, fundamentado teórica e metodologicamente, denominado Unidades Didáticas Multiestratégicas (UDM). Enquanto modelo de planejamento de projeto de ensino e aprendizagem, a UDM abrange a integração, de modo organizado e sequenciado, de um conjunto de estratégias didáticas e de avaliação de acordo com objetivos de aprendizagem previamente definidos e delimitados a partir de uma dada abordagem metodológica.

Para Sanmartí (2009), a utilização de múltiplas estratégias didáticas no planejamento e desenvolvimento de UD se faz necessária por diversas razões, dentre elas: i) utilizar estratégias diversas implica dar maiores oportunidades para a construção de conhecimentos; ii) a diversidade de atividades possibilita que mais alunos encontrem aquela que melhor os ajude a aprender; iii) a diversidade de estratégias possibilita maior motivação e desperta o interesse dos alunos.

Nesse contexto, este artigo apresenta três grandes intenções. A primeira refere-se à compreensão de possíveis alterações no enfoque curricular de uma UDM por um grupo de professores de Química em formação inicial, bem como a análise do processo de 


\section{-Revista de Iniciação à Docência, v.6, n.2, 2021- \\ Publicação: dezembro, 2021 - ISSN 2525-4332}

reorganização contínua do conhecimento profissional docente. Já a segunda, pretende expor os impactos de um movimento formativo de ação crítica e reflexão no replanejamento da UDM dos professores em formação inicial a partir da fase de uma intervenção didático-pedagógico particular. E, por fim, pretende-se integrar os dados empíricos desse movimento de implementação da UDM com o objetivo de responder à seguinte questão de pesquisa "Como o movimento de crítica e reflexão sobre a ação impacta no replanejamento da UDM dos professores de Química em formação inicial?”.

\section{Aportes teóricos}

Conforme os pressupostos do próprio modelo de planejamento de UDM, é possível afirmar que professores de ciências, em formação inicial ou continuada, expressam formalmente suas ideias prévias ao longo da etapa de planejamento mediante a realização de cada uma das tarefas exigidas em sua elaboração. Isso se dá na medida em que explicitam objetivos de aprendizagem, definição e estruturação das estratégias didáticas e de avaliação, bem como suas relações com a abordagem metodológica escolhida (BEGO, 2016; BEGO; SGARBOSA, 2016).

Por sua vez, uma das categorias apresentadas por Porlán e Rivero (1998) para a análise de UD planejadas por professores envolve perspectivas sobre o ensino em um campo conceitual concreto e suas relações com a epistemologia do trabalho didáticopedagógico. Tal categoria foi denominada como Enfoques Curriculares.

Desse modo, defende-se que os conhecimentos explicitados no planejamento de uma UDM podem ser investigados por meio da análise dos níveis de formulação nas diferentes categorias curriculares, conforme proposto por Porlán e Rivero (1998).

Os Enfoques Curriculares derivam dos modelos didáticos propostos pelos autores (tradicional, tecnicista, espontaneísta e alternativo) e dão significado a três diferentes subcategorias, quais sejam, conteúdos, metodologia e avaliação do plano de ensino do professor. O Quadro 1 apresenta seus níveis de formulação e propriedades.

Quadro 1: Níveis de formulação das diferentes categorias curriculares.

\begin{tabular}{|c|c|c|c|}
\hline \multirow[b]{2}{*}{ SUBCATEGORIAS } & \multicolumn{3}{|c|}{ ENFOQUE CURRICULAR (Níveis de formulação) } \\
\hline & $\begin{array}{l}\text { Enfoque } \\
\text { tradicional }\end{array}$ & $\begin{array}{l}\text { Enfoque tecnicista } \\
\text { lespontaneísta }\end{array}$ & $\begin{array}{l}\text { Enfoque alternativo } \\
\text { (construtivista e } \\
\text { investigativo) }\end{array}$ \\
\hline \multirow{2}{*}{$\begin{array}{l}\text { CONTEÚDOS } \\
\text { - Níveis de formulação } \\
\text { - Amplitude e } \\
\text { diversidade } \\
\text { - Organização }\end{array}$} & \multirow{2}{*}{$\begin{array}{l}\text { O conteúdo do } \\
\text { conhecimento } \\
\text { escolar como } \\
\text { adaptação do } \\
\text { conhecimento } \\
\text { disciplinar }\end{array}$} & $\begin{array}{l}\text { O conteúdo do } \\
\text { conhecimento escolar } \\
\text { como adaptação do } \\
\text { conhecimento disciplinar }\end{array}$ & \multirow{2}{*}{$\begin{array}{l}\text { O conteúdo do } \\
\text { conhecimento escolar como } \\
\text { reelaboração e integração } \\
\text { de conhecimento que } \\
\text { procedem de diversas } \\
\text { fontes }\end{array}$} \\
\hline & & $\begin{array}{l}\text { O conteúdo do } \\
\text { conhecimento escolar } \\
\text { como adaptação }\end{array}$ & \\
\hline
\end{tabular}


-Revista de Iniciação à Docência, v.6, n.2, 2021-

Publicação: dezembro, 2021 - ISSN 2525-4332

\begin{tabular}{|c|c|c|c|}
\hline \multirow{3}{*}{ SUBCATEGORIAS } & \multicolumn{3}{|c|}{ ENFOQUE CURRICULAR (Níveis de formulação) } \\
\hline & \multirow[t]{2}{*}{$\begin{array}{l}\text { Enfoque } \\
\text { tradicional }\end{array}$} & $\begin{array}{l}\text { Enfoque tecnicista } \\
\text { lespontaneísta }\end{array}$ & \multirow[t]{2}{*}{$\begin{array}{l}\text { Enfoque alternativo } \\
\text { (construtivista e } \\
\text { investigativo) }\end{array}$} \\
\hline & & $\begin{array}{l}\text { contextual do } \\
\text { conhecimento cotidiano }\end{array}$ & \\
\hline \multirow{2}{*}{$\begin{array}{l}\text { METODOLOGIA } \\
\text { - Papel didático das } \\
\text { concepções dos alunos } \\
\text { - Caracterização das } \\
\text { atividades } \\
\text { - Interação professor- } \\
\text { aluno }\end{array}$} & \multirow{2}{*}{$\begin{array}{l}\text { Baseada na } \\
\text { transmissão verbal } \\
\text { de conhecimento } \\
\text { por parte do } \\
\text { professor } \\
\text { enquanto os } \\
\text { alunos atendem ou } \\
\text { realizam atividade } \\
\text { de comprovação } \\
\text { do explicado }\end{array}$} & $\begin{array}{l}\text { Baseada na versão forte } \\
\text { (indutivista) do } \\
\text { empirismo. Os objetivos } \\
\text { como fio condutor das } \\
\text { atividades }\end{array}$ & \multirow[t]{2}{*}{$\begin{array}{l}\text { A pesquisa dos problemas } \\
\text { de potencial interesse é o } \\
\text { que confere sentido nas } \\
\text { atividades, sendo as ideias } \\
\text { dos alunos uma referência } \\
\text { contínua do processo }\end{array}$} \\
\hline & & $\begin{array}{l}\text { Baseada na versão fraca } \\
\text { do empirismo. Os } \\
\text { interesses dos alunos } \\
\text { como fio condutor das } \\
\text { atividades }\end{array}$ & \\
\hline \multirow{2}{*}{$\begin{array}{l}\text { AVALIAÇÃO } \\
\text { - Finalidade } \\
\text { - Conteúdo } \\
\text { - Instrumentos }\end{array}$} & \multirow{2}{*}{$\begin{array}{l}\text { A avaliação como } \\
\text { qualificação para } \\
\text { comprovar que os } \\
\text { alunos se } \\
\text { apropriaram dos } \\
\text { conceitos } \\
\text { explicados }\end{array}$} & $\begin{array}{l}\text { A avaliação como medida } \\
\text { do grau de realização dos } \\
\text { objetivos }\end{array}$ & \multirow{2}{*}{$\begin{array}{l}\text { A avaliação como pesquisa } \\
\text { para ajustar o ensino e a } \\
\text { aprendizagem (ou seja, a } \\
\text { pressuposição de } \\
\text { conhecimento escolar } \\
\text { desejável e a evolução real } \\
\text { das ideias dos alunos) }\end{array}$} \\
\hline & & $\begin{array}{l}\text { A avaliação como } \\
\text { participação da dinâmica } \\
\text { da classe }\end{array}$ & \\
\hline
\end{tabular}

Fonte: Adaptado de Porlán e Rivero (1998).

A partir desses referenciais, é possível verificar o estágio de desenvolvimento em que se encontram os futuros professores que participaram de uma atividade formativa pautada no planejamento autoral e autônomo.

Tais expectativas exigem desse tipo de proposta formativa uma atenta observação das intenções dos professores em formação, pois, conforme já apontado na literatura (BEGO, 2017; PORLÁN; RIVERO, 1998), podem ser verificadas ideias heterogêneas, conflitantes e ampla diversidade de ideias que podem atuar obstaculizando tanto a coerência interna como o processo de inovação do planejamento de ensino.

\section{Procedimentos metodológicos}

A presente pesquisa de caráter qualitativo (LÜDKE; ANDRÉ, 1986) foi realizada no decorrer das disciplinas Instrumentalização para o Ensino de Química e Estágio Curricular Supervisionado $\mathrm{V}$, ministradas, respectivamente, no primeiro e segundo semestres de 2016 no âmbito dos componentes curriculares ofertados em um curso de Licenciatura em Química de uma universidade pública brasileira. 


\section{-Revista de Iniciação à Docência, v.6, n.2, 2021- \\ Publicação: dezembro, 2021 - ISSN 2525-4332}

Esta investigação engloba considerações acerca de como o processo de implementação de UDM incide no desenvolvimento do conhecimento prático-profissional de professores de Química em formação inicial.

Nesse sentido, considera-se a natureza do objeto de estudo desta pesquisa como um Estudo de Caso, pois envolveu: uma análise em profundidade acerca do processo de implementação de UDM; a apresentação de uma proposta de investigação válida, na medida em que houve, como preocupação central, a intenção de compreender de forma holística e aprofundada determinado contexto formativo singular e historicamente situado; a descrição de um contexto real em que se considera a multiplicidade de dimensões expostas em problema; a utilização de profusas fontes de informação coletadas em diferentes momentos da pesquisa; a consideração de que generalizações e apontamentos de situações representativas podem ser extrapolados para contextos e situações análogas; a criação de um banco de dados produzidos a partir de transcrições, entrevistas, notas de campo, documentos, grupos focais, gravações de áudio e vídeo (LÜDKE; ANDRÉ, 1986; YIN, 2001; GIBBS, 2009).

Mais especificamente, esse trabalho é resultado de um recorte de uma pesquisa mais ampla que resultou em uma tese de doutorado. Assim sendo, o presente trabalho envolveu a utilização de categorias que são oriundas das propostas de Porlán e Rivero (1998) para se avaliar o Enfoque Curricular adotado por professores de Química ao planejarem e replanejarem uma UDM.

Em termos do levantamento de dados para este texto, foram constituídas diferentes ideias de licenciandos acerca dos processos de planejamento, aplicação e replanejamento envolvidos na implementação das UDM. A convergência das ações propostas pretendia gerar constantes estados crítico-reflexivos nos licenciandos e estimulá-los ao desenvolvimento de conhecimento prático-profissional (PORLÁN; RIVERO, 1998).

Dos 16 alunos matriculados nas disciplinas ministradas no primeiro e segundo semestre de 2016, 15, efetivamente, concluíram o percurso formativo de implementação de UDM. Nesse processo, os alunos foram divididos em quatro grupos, sendo que três eram compostos por quatro alunos e um grupo de três alunos para executar as atividades propostas pelo professor formador. Diante disto e, considerando a grande quantidade de dados gerada e os limites de espaço disponíveis, para este artigo definiu-se pela investigação particular de apenas um dos grupos em razão dos seguintes fatores: i) proposta de partida singular de planejamento, pautada no argumento de rompimento com tendências mais tradicionais e assentada na abordagem metodológica do Ensino por Investigação (CARVALHO, 2013); ii) alto entrosamento dos membros do grupo para realização das atividades da disciplina; ii) menor nível de interferência de fatores externos e maior nível de continuidade na etapa de aplicação da UDM. Portanto, em virtude dessas 


\section{-Revista de Iniciação à Docência, v.6, n.2, 2021- \\ Publicação: dezembro, 2021 - ISSN 2525-4332}

considerações, o grupo, cuja UDM foi planejada com temática "Química Nuclear: O misterioso caso Black", fez parte da amostra desta investigação.

Segundo a proposta de Bego (2016), o processo de implementação de uma UDM compreende três etapas integradas: a primeira consiste no planejamento da UDM; a segunda se refere à própria intervenção didático-pedagógica em sala de aula; e a última abarca o replanejamento da UDM a partir da reflexão crítica mediada acerca da intervenção realizada. Ademais, a proposta adotada para aplicação da UDM foi no formato de minicursos. Segundo Carvalho (2013), esse tipo de proposta sustenta uma perspectiva afastada da transmissão direta de conteúdos e da explicação centrada no professor e na realização de exercícios.

Ao longo da implementação foram geradas duas diferentes versões para a UDM, sendo consideradas os modos pré e pós-aplicação. Assim, tais propostas constituem o primeiro conjunto de documentos de pesquisa delimitados.

Antes do processo de replanejamento da UDM, os professores em formação inicial participaram de um Grupo Focal (GF). Essa técnica, conforme aponta Babour (2009), envolve discussões grupais fomentadas por um moderador capaz de instigar interações em um grupo, de forma que sua amostragem exponha suas atitudes, crenças, valores e contradições de forma espontânea.

Para análise da diversidade de dados gerados, optou-se pela utilização da Análise de Conteúdo (AC) de Bardin (2016). A análise temática do conteúdo, conforme assegura a autora, desdobra-se em três fases. A primeira, relativa à fase de pré-análise, a segunda referente à exploração do material, e a terceira alusiva ao tratamento de dados obtidos/ interpretação.

A etapa da pré-análise encerra a leitura flutuante que compreende o primeiro contato com os documentos a serem analisados; a composição do corpus de análise; e, a elaboração e reelaboração de inferências. A exploração do material, apresenta a categorização de expressões ou palavras significativas. Assim, em uma pesquisa qualitativa típica, as categorias ganham destaque. Essas categorias podem ser definidas antes da coleta de dados (categorias a priori) ou após essa ação (categorias a posteriori) (BARDIN, 2016).

As categorias pré-estabelecidas, categorias a priori, envolvem, inicialmente, a preparação dos instrumentos de pesquisa e, subsequentemente, ações relacionadas à ida a campo pelo pesquisador para a coleta de dados; descrição das informações obtidas; e, apresentação de conclusões para os fatos. Destaca-se que, para essa proposta, a fundamentação teórica é quem conduz a pesquisa qualitativa. Já as categorias a posteriori compreendem a redução de dados brutos em dados classificados por meio dos processos metódicos de seleção, foco, simplificação e sumarização. A finalidade dessas 


\section{-Revista de Iniciação à Docência, v.6, n.2, 2021- \\ Publicação: dezembro, 2021 - ISSN 2525-4332}

ações é de separar os dados obtidos em blocos com conteúdos semelhantes (BARDIN, 2016).

A última etapa corresponde ao tratamento dos resultados de forma a torná-los significativos. Nessa fase cabem a proposição de inferências, interpretações, correlações entre evidências inventariadas, as fundamentações teóricas adotadas e o escopo conjecturado (BEGO, 2013; CAVALCANTE; CALIXTO; PINHEIRO, 2014; BARDIN, 2016)

Em conformidade com Medeiros e Amorim (2017), a escolha desse tipo de análise textual tem relação com o fato da $A C$, nesta pesquisa, pretender captar o processo de implementação de UDM por professores em formação inicial, impondo para isso uma análise na qual as ações descritivas são primordiais no estabelecimento de categorias e para procedimentos interpretativos, sem uma demanda específica pela transformação da realidade a partir das perspectivas dos sujeitos que participaram da investigação.

Para esse fim, os procedimentos metodológicos da AC propostos por Bardin (2016) foram empregados para a análise textual dos dados obtido pelos diferentes instrumentos (Questionários, Roteiros de Observação, Roteiro de Análise Textual (RAT), Entrevistas e Grupos Focais) juntos às fontes de informação.

Para os Questionários recorreu-se à análise de conteúdo para investigar o conjunto de questões que versaram sobre as ideias prévias do planejamento didáticopedagógico. Assim, após a etapa de leitura flutuante dos textos, definiu-se pela utilização de, conforme a classificação proposta por Bardin (2016), categorias a posteriori para analisar as dimensões epistemológica e didático-pedagógica.

Já os Roteiros de Observação correspondem a um rico conjunto de descrições acerca das condutas dos indivíduos no contexto coletivo, estipula-se forte tendências a juízos de valor, daí, então, comporem material suplementar aos instrumentos de coleta de informações. Sua análise envolve o uso de categorias a posteriori para identificar elementos constitutivos de ações práticas ao longo do desenvolvimento das atividades de elaboração, aplicação, reelaboração e reflexão das propostas formativas envolvidas.

O RAT foi empregado para orientar a coleta de informações nas UDM. Sua intenção é guiar o processo de análise das propostas teóricas que antecedem e sucedem a implementação do planejamento didático-pedagógico. Nesse sentido, recorre-se à fundamentação teórica proposta por e Porlán e Rivero (1998), Bego e Sgarbosa (2016) e Bego (2016) relativas à análise das temáticas - conteúdos, metodologias e avaliação presentes nas UDM. Assim, após a etapa de leitura flutuante dos textos, utilizou-se de categorias a priori relativas às concepções epistemológicas dos professores definidas pelos autores espanhóis para caracterização das duas versões da UDM planejada.

As Entrevistas foram gravadas e transcritas. Após a leitura flutuante dos textos gerados, adotou-se o uso de categorias a priori para analisar envolvimento; 


\section{-Revista de Iniciação à Docência, v.6, n.2, 2021- \\ Publicação: dezembro, 2021 - ISSN 2525-4332}

comprometimento; mobilização de conhecimentos prático-profissionais; e as perspectivas crítico-reflexivas envolvidas no desenvolvimento de ações teóricofundamentadas ligadas ao planejamento didático-pedagógico. Na análise dos Grupos Focais foram utilizadas as transcrições do processo de argumentação gerado entre os membros do grupo. Assim, após a etapa de leitura flutuante dos textos, definiu-se pela utilização de categorias a posteriori para identificar evoluções de ações práticoprofissionais e crítico-reflexivas acerca das dificuldades para a composição do conhecimento profissional docente e de compreensões dos enfoques curriculares previstos por Porlán e Rivero (1998).

$\mathrm{Na}$ análise dos Grupos Focais foram utilizadas as transcrições do processo de argumentação gerado entre os membros do grupo. Assim, após a etapa de leitura flutuante dos textos, definiu-se pela utilização de categorias a posteriori para identificar evoluções de ações prático-profissionais e crítico-reflexivas acerca das dificuldades para a composição do conhecimento profissional docente e de compreensões dos enfoques curriculares previstos por Porlán e Rivero (1998).

\section{Resultados e Discussão}

\section{Conhecimentos explicitados na primeira versão da UDM}

A intenção desta seção está em expor os conhecimentos explicitados pelos licenciandos no planejamento da primeira versão da UDM. A condução dessa análise deuse por meio do RAT, conforme Bego (2017). O conteúdo é apreciado em seu nível de formulação, sua amplitude e diversidade, e em sua organização. Para a metodologia são examinados o papel didático das ideias dos alunos, a caracterização das atividades e a interação professor-alunos. E, finalmente, para a avaliação são observados finalidade, conteúdo considerado e instrumentos propostos. Em cada uma dessas subcategorias é possível depreender qual tipo de enfoque é adotado pelos sujeitos para a composição do planejamento de ensino: tradicional, tecnicista, espontaneísta ou alternativo (PORLÁN; RIVERO, 1998).

A partir desses referenciais, a intenção é verificar o estágio de desenvolvimento em que se encontram os futuros professores que participaram da atividade formativa que apresentou a elaboração da primeira versão da UDM como uma possibilidade de planejamento autoral e autônomo.

Isto posto, para a análise das subcategorias conteúdo, metodologia e avaliação, em conformidade com o referencial adotado, considera-se o conjunto de tarefas (Figura 1) previsto para a elaboração da UDM (BEGO; SGARBOSA, 2016). São analisadas as seções "Tema, objetivos de aprendizagem, sequências didáticas e estratégias de avaliação" e "Seleção das estratégias didáticas e estratégias de avaliação". 
Figura 1: Sistematização do planejamento da Unidade Didática Multiestratégica.

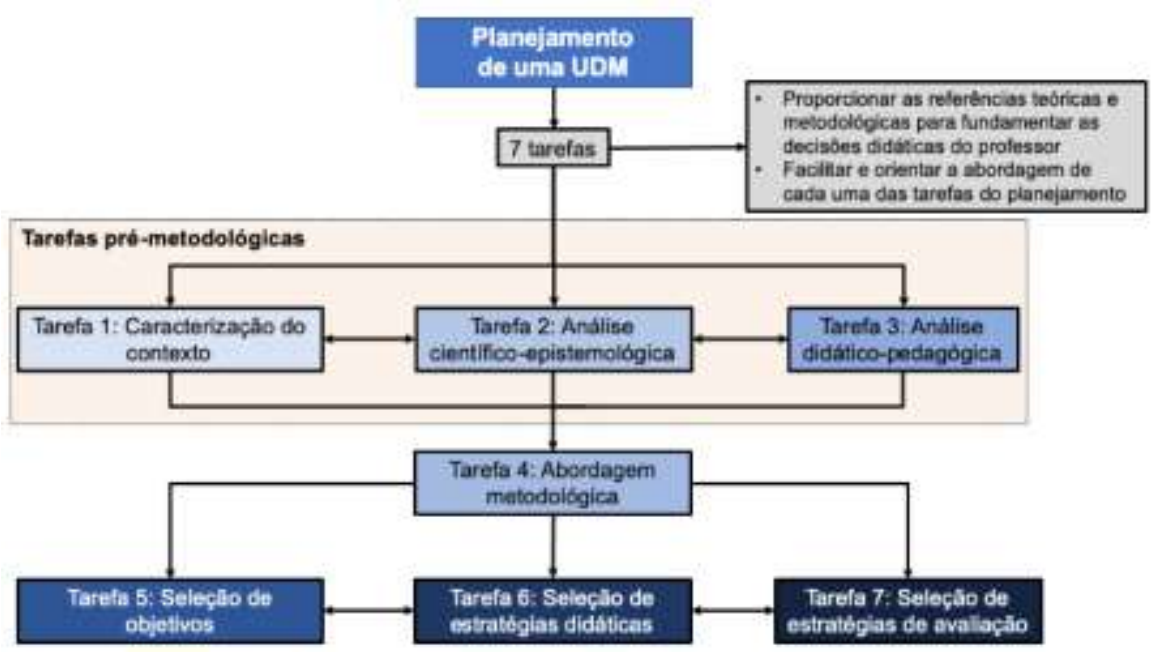

Fonte: Extraído de Bego, Ferrarini e Moralles (2021)

O grupo de licenciandos havia definido como abordagem metodológica o Ensino por Investigação, fundamentado nas discussões de Carvalho (2013). Essa abordagem metodológica apresenta a finalidade de desenvolver habilidades cognitivas nos alunos, realizar procedimentos como a elaboração de hipóteses, a anotação e análise de dados e fortalecer a capacidade argumentativa dos estudantes.

Assim, partindo dos princípios da abordagem metodológica escolhida, para planejar a seção, os licenciandos optaram pelo tema "Química nuclear: o misterioso caso Black”. Esse tema está associado justamente à principal estratégia definida pelos estudantes para estruturar o ensino investigativo proposto: um estudo de caso interrompido (SÁ; FRANCISCO; QUEIROZ, 2007).

Em função das exigências do próprio modelo de planejamento da UDM, os licenciandos precisavam definir os objetivos de aprendizagem almejados e, posteriormente, as partes do conteúdo programático correspondente. No Quadro 2 identifica-se que o conteúdo escolar "radioatividade" foi distribuído em três Sequências Didáticas (SD) e que o objetivo geral e os objetivos específicos e os conteúdos curriculares se distribuem com o tema da UDM. 
-Revista de Iniciação à Docência, v.6, n.2, 2021-

Publicação: dezembro, 2021 - ISSN 2525-4332

Quadro 2. Primeira versão da UDM do Grupo 1.

\begin{tabular}{|c|c|c|}
\hline Tema da UDM & \multicolumn{2}{|l|}{ Química nuclear: o misterioso caso Black. } \\
\hline $\begin{array}{l}\text { Objetivo da } \\
\text { UDM }\end{array}$ & \multicolumn{2}{|c|}{$\begin{array}{l}\text { Avaliar os impactos da radiação no organismo humano, checando os diferentes sintomas } \\
\text { provocados pela exposição a diversas emissões radioativas em um laudo pericial. }\end{array}$} \\
\hline SD & Objetivo da SD & Conteúdo Programático \\
\hline $\begin{array}{l}\text { Um atleta! Uma } \\
\text { glória! Uma } \\
\text { morte! }\end{array}$ & $\begin{array}{l}\text { Entender as reações nucleares, } \\
\text { comparando as ideias prévias sobre a } \\
\text { radioatividade com os conceitos de } \\
\text { estabilidade e instabilidade do nuclídeo. }\end{array}$ & $\begin{array}{l}\text { - Estabilidade e Instabilidade do nuclídeo } \\
\text { - Radionuclídeo } \\
\text { - Reações nucleares e suas aplicações } \\
\text { pacíficas e bélicas }\end{array}$ \\
\hline $\begin{array}{l}\text { Parece, mas } \\
\text { não é! }\end{array}$ & $\begin{array}{l}\text { Entender os conceitos de fissão e fusão } \\
\text { nuclear e seu uso socioeconômico, } \\
\text { explicando o princípio do funcionamento } \\
\text { das usinas nucleares e armas nucleares. }\end{array}$ & $\begin{array}{l}\text { - Fissão nuclear e suas aplicações } \\
\text { - Fusão nuclear e suas aplicações }\end{array}$ \\
\hline $\begin{array}{l}\text { O que } \\
\text { aconteceu com } \\
\text { Black? }\end{array}$ & $\begin{array}{l}\text { Analisar os impactos de diferentes } \\
\text { emissões radioativas no organismo } \\
\text { humano, atribuindo aos sintomas às } \\
\text { características das emissões e a } \\
\text { quantidade de radiação em que o corpo } \\
\text { foi exposto. }\end{array}$ & $\begin{array}{l}\text { - Reação nuclear: desintegração } \\
\text { - Tipos de emissão }(\alpha, \beta, \gamma) \text {, suas } \\
\text { características e impactos na saúde humana } \\
\text { - Cálculo de meia-vida }\end{array}$ \\
\hline
\end{tabular}

Fonte: Elaboração própria

Interessante destacar que a explicitação dos objetivos nas três SD mostra intenções do grupo em buscar a integração entre conteúdos atitudinais, procedimentais e conceituais. Como decorrência, ao contrário do que foi identificado majoritariamente na empiria realizada por Porlán e Rivero (1998), o grupo de licenciandos não apresentou um planejamento constituído de um conjunto acumulativo e fragmentado de conceitos, leis e teorias estruturados como uma versão simplificada e dogmática do conteúdo disciplinar presente tradicionalmente nos livros didáticos. Ademais, os conteúdos não se organizam linearmente na forma de listagens e sem relação entre eles. Ao contrário, os conteúdos se relacionam diretamente com os objetivos de aprendizagem delimitados e estão adequadamente integrados a fim de fornecerem fundamentos para a consecução do objetivo geral de aprendizagem da UDM. Os conteúdos são, por isso, organizados em torno de um problema relevante, o caso Black, para o contexto escolar, de modo a integrar conhecimentos procedentes de diferentes fontes (livro didático, caso, notícias, blogs, sites de internet). Esse conjunto de dados, permite inferir que a primeira versão da UDM foi planejada pelo grupo de licenciandos com um enfoque curricular alternativo para o conteúdo.

Diante desse resultado de pesquisa, aponta-se para a possível influência decisiva da tarefa 2 do planejamento de uma UDM. Para a análise científico-epistemológica o grupo de licenciandos precisou pesquisar e explicitar os pré-requisitos para o trabalho com o conteúdo do conhecimento escolar a ser abordado na UDM. Sequencialmente, o grupo apresentou o conteúdo conceitual, em conformidade com a explicitação dos fatos 


\section{-Revista de Iniciação à Docência, v.6, n.2, 2021- \\ Publicação: dezembro, 2021 - ISSN 2525-4332}

de interesse (nível fenomenológico, teórico e representacional) e capaz de contemplar a organização de ideias, conceitos e informações de modo esquematizado. A atividade avança diante da proposta de compor conteúdos procedimentais para analisar os resultados obtidos, nesse sentido os licenciandos propuseram, ordenadamente, o levantamento de hipóteses, teste de hipóteses, sistematização e aplicação. Seguindo a prescrição, são apresentados os conteúdos atitudinais com a intenção de formação de valores em relação à informação recebida e de possíveis intervenções dos alunos na realidade. Para isso, o grupo considerou a importância de saber avaliar quais os tipos de emissão nuclear e seus impactos nos seres vivos, principalmente humanos e saber diferenciar acidente, contaminação e bombas nucleares. A tarefa é finalizada com a apresentação das referências bibliográficas. Desse modo, quando da delimitação e organização do conteúdo, os licenciandos já possuíam uma visão bastante ampla do conteúdo escolar a ser trabalhado que envolvia sua divisão nas dimensões conceitual, procedimental e atitudinal, bem como suas inter-relações. Isso provavelmente forneceu subsídios teóricos decisivos para a proposta de enfoque curricular dada ao conteúdo no planejamento da UDM.

Importante ressaltar que a metodologia corresponde ao cerne do planejamento na medida em que orienta a escolha e a estruturação dos seus elementos constituintes. Esse componente do Enfoque Curricular incorpora os princípios e convicções relativos aos processos de ensino e aprendizagem, concepções da natureza da ciência e os objetivos educacionais de um dado nível e modalidade escolar.

O inédito estudo de caso interrompido formulado pelo grupo se refere à morte de um atleta olímpico após a participação nos Jogos Olímpicos do Rio de Janeiro em 2016. Descreve-se, ainda, que os alunos seriam divididos em grupos e que cada um desses coletivos precisaria investigar acerca da morte do esportista e, ao final, produzir um laudo pericial com a resolução do caso.

A análise do Enfoque Curricular em relação à subcategoria metodologia compreende ponderações sobre as propostas de planejamentos escolares, segundo Porlán e Rivero (1998). O confronto entre os dados apresentados pelos autores espanhóis acerca da caracterização da metodologia dos planejamentos de professores em formação e os obtidos nesta pesquisa se revelam divergentes. Isso se deve ao fato da UDM elaborada explicitar tendências para a elaboração de conhecimentos científicos e atividades didáticas direcionadas à investigação de problemas; desconsiderar a transmissão verbal de conteúdos como fator relevante ao Ensino de Ciências; e destacar o interesse da utilização das ideias dos alunos como uma referência contínua dos processos de ensino e aprendizagem. Já as interações professor-aluno, propostas nessa primeira versão, distanciam-se de relações unidirecionais e apontam para a importância do papel do professor como mediador nos processos de ensino e aprendizagem; para uma versatilidade de orientações que envolvem a realização de debates, discussões 


\section{-Revista de Iniciação à Docência, v.6, n.2, 2021- \\ Publicação: dezembro, 2021 - ISSN 2525-4332}

coletivas e o uso das ideias prévias dos alunos como compromisso ininterrupto ao longo do desenvolvimento da prática docente. Entende-se que, no geral, os sujeitos buscaram vias didáticas que se afastaram do enfoque tradicional e se aproximaram de um enfoque alternativo.

Pode-se apontar para a importância da tarefa 4 do planejamento de uma UDM que envolve a necessária definição e explicitação dos princípios de uma abordagem metodológica específica. Isso resultou na necessidade de os licenciandos proporem um planejamento que fosse coerente com os princípios pedagógicos que fundamentam a abordagem escolhida. Assim, evidencia-se uma postura crítica e fundamentada teoricamente para a proposição da organização do ensino e o não direcionamento para o mero cumprimento burocrático das tarefas pedagógicas exigidas pela UDM.

A próxima subcategoria a ser analisada quanto ao enfoque curricular se refere à avaliação. O Quadro 3 apresenta a seleção de estratégias de avaliação do Grupo 1 na primeira versão da UDM.

Quadro 3. Estratégias de avaliação de acordo com cada sequência didática da UDM do Grupo 1.

\begin{tabular}{l} 
Estratégias de Avaliação \\
\hline A avaliação será formativa, pois a metodologia Ensino por Investigação utiliza essa concepção de avaliação. Para \\
a avaliação dessa SD, os alunos deverão fazer anotações sobre suas ideias prévias e pesquisas relacionadas aos \\
conceitos envolvidos nessa sequência e para isso utilizarão o Ambiente Virtual de Avaliação (AVA) EdModo, pois \\
com esse AVA podemos dar feedback para cada atividade dos alunos.
\end{tabular}

Fonte: Elaboração própria

Os dados apresentam destaque para pretensões de realização da avaliação formativa ao longo das SD em virtude de a metodologia Ensino por Investigação ter sido adotada. De fato, a estratégia adotada guarda coerência com a abordagem escolhida e repete-se continuamente o uso das ideias prévias e de pesquisas relacionadas aos conceitos envolvidos na SD. Ao longo das SD, reiteradamente, são exibidas informações relativas à entrega e correção de tarefas por meio da plataforma EdModo como AVA.

Contudo, não ocorre a explicitação de instrumentos específicos para a realização da avaliação, apenas o meio, no caso um TIC, em que se realizaria a entrega de cada atividade. Cada uma das atividades a ser realizada não é explicitada, nem mesmo qual seria sua relação com os tipos de conteúdo - conceitual, procedimental, atitudinal - a serem avaliados e acompanhados. Também não se observa qualquer menção clara acerca de um processo avaliativo que fornecesse informações concretas para o aperfeiçoamento do próprio planejamento de ensino. Em que pese a escolha e explicitação da adoção de uma perspectiva formativa para a avaliação da UDM, essa ausência de instrumentos específicos demonstra que a avaliação se aproxima da prática de acompanhamento espontâneo da participação dos alunos na dinâmica da aula. Não são encontrados elementos que apontem caracteristicamente para a avaliação como um processo contínuo de melhoria, tanto a aprendizagem como do ensino, mediante informações obtidas de diferentes fontes, ou seja, a avaliação da hipótese do 


\section{-Revista de Iniciação à Docência, v.6, n.2, 2021- \\ Publicação: dezembro, 2021 - ISSN 2525-4332}

conhecimento escolar desejável e a evolução real das ideias dos alunos (PORLÁN; RIVERO, 1998). Com efeito, a análise desse conjunto de características permite inferir que um enfoque curricular marcadamente espontaneísta.

Mesmo assim, isso destoa dos principais resultados empíricos de Porlán e Rivero (1998) que remetem ao fato de que propostas avaliativas são coerentes com um enfoque tradicional, qual seja, comprovação de aprendizagens conceituais mediante a utilização de provas escritas. Vale trazer aqui o fato de que Sánchez Blanco e Valcárcel Pérez (1993) manifestam que entendimentos e decisões relativos à avaliação são fortemente vinculados às ideias que os professores têm sobre os processos de ensino e aprendizagem. Trata-se, por isso, de uma dimensão complexa do planejamento na medida em que pode representar tanto possíveis inconsistências quanto concebíveis desarticulações internas com o conteúdo ou a metodologia que foram definidos.

Em suma, a interação entre o conhecimento relativo ao conteúdo específicos e ao conhecimento didático-pedagógico foi capaz, no geral, de permitir a elaboração de uma proposta curricular caracterizada por mudanças no paradigma da seleção de atividades. Os sujeitos desta pesquisa não recorreram à utilização de livros didáticos como referenciais únicos para a seleção de conteúdos; não adotaram uma sequência linear e acumulativa de conteúdos, organizados segundo a lógica disciplinar características dos livros didáticos; não aderem a uma sequência fechada de atividades de observação no laboratório; e, não propõem reduzidamente a realização de provas escritas para comprovar se os alunos conseguiram adquirir os conhecimentos previamente estabelecidos.

Para Porlán e Rivero (1998, p. 284), professores em formação inicial resistem a enfoques mais alternativos, por não terem vivenciado práticas alternativas, e continuam a insistir em práticas nas quais foram submetidos por, provavelmente, não possuírem "elementos teórico-práticos para transladar para abordagens inovadoras para o ensino de um campo conceitual concreto".

Em sentido contrário a essa posição, advoga-se, em função dos dados obtidos, que o modelo de planejamento da UDM pode representar potencial estímulo aos professores em formação para inovar diante de uma proposta de planejamento pautada em teorias pedagógicas complexas, contemporâneas e alicerçada na definição e explicitação de uma abordagem metodológica como eixo nevrálgico. Isso pode suceder em uma vivência formativa alternativa nos termos dos enfoques curriculares, e promover mudanças na imagem da ciência, na composição de modelos didáticos pessoais e nos entendimentos relativos a teorias de aprendizagem.

Em definitivo, os professores de química em formação participantes desta investigação, em virtude da execução de tarefas específicas para o planejamento não 


\section{-Revista de Iniciação à Docência, v.6, n.2, 2021- \\ Publicação: dezembro, 2021 - ISSN 2525-4332}

realizaram a mera reprodução de uma visão acumulativa, fragmentária e não interativa de conteúdos disciplinares para a elaboração do planejamento didático-pedagógico.

\section{Conhecimentos explicitados na segunda versão da UDM}

A opção analítica adotada nesta seção é mostrar preliminarmente os trechos modificados entre as versões da UDM e compará-los. Posteriormente, apresentam-se inferências que pretendem classificar e verificar a manutenção ou a modificação do tipo de enfoque curricular escolhido para a elaboração de um novo planejamento de ensino, bem como a comparação com os resultados empíricos apresentados em Porlán e Rivero (1998).

O Quadro 4 exibe o comparativo entre os Objetivos Específicos, as Estratégias Didáticas e as Estratégias de Avaliação. A apresentação dos dados refere-se aos trechos que foram efetivamente modificados na segunda versão do planejamento.

Quadro 4. Segunda versão da UDM do Grupo 1.

\begin{tabular}{|l|}
\hline \multicolumn{1}{|c|}{ Objetivos Específicos } \\
\hline $\begin{array}{l}\text { SD III: Analisar os impactos de diferentes emissões radioativas no organismo humano, atribuindo os } \\
\text { sintomas às características das emissões. }\end{array}$ \\
\hline \multicolumn{1}{|c|}{ Estratégias Didáticas } \\
\hline $\begin{array}{l}\text { SD II: Estudo de Caso; TIC (Tecnologias da Informação e Comunicação); CTS (Ciência, Tecnologia e } \\
\text { Sociedade) }\end{array}$ \\
\hline \multicolumn{1}{c|}{ Estratégias de Avaliação } \\
\hline $\begin{array}{l}\text { SD I, II e III: Para a avaliação dessa SD, os alunos deverão fazer anotações sobre suas concepções prévias e } \\
\text { pesquisas relacionadas aos conceitos envolvidos nessa sequência, uma breve explicação sobre como esses } \\
\text { tipos de reações nucleares poderiam ou não estar ligadas ao crime, uma produção de um laudo técnico } \\
\text { pericial explicando a morte do atleta e durante a sistematização do conteúdo será realizado o feedback. } \\
\text { Também avaliaremos a participação dos estudantes durante as discussões das aulas da SD. }\end{array}$ \\
\hline
\end{tabular}

Fonte: Elaboração própria

A modificação no Objetivo Específico da SD III envolveu a alteração na quantidade de radiação ao qual o corpo foi exposto. Essa modificação mostra aos licenciandos a importância de um planejamento que pode e deve ser remodelado de acordo com as convicções advindas da reflexão sobre a prática, conforme se discute na próxima seção.

Essa modificação revela que os licenciandos identificaram aspectos do conteúdo que não poderiam ser adequadamente desenvolvidos - a quantidade de radiação emitida por um radioisótopo - para a resolução do estudo de caso com estudantes de ensino médio. Ademais, a referida supressão de conceitos na nova SD III parece compor a explicitação da integração de saberes que tem como qualificadores a resolução de problemas; o potencial inerente ao processo crítico e reflexivo sobre a ação; a explicitação e, até mesmo, a superação de perspectivas atreladas ao senso comum; e, da compreensão da importância das correlações entre as concepções disciplinares e as intenções da proposta formativa em contexto. 


\section{-Revista de Iniciação à Docência, v.6, n.2, 2021- \\ Publicação: dezembro, 2021 - ISSN 2525-4332}

Assevera-se, assim, que nessa nova versão da UDM são conservadas: perspectiva de programação sistemática e explícita; integração dos conteúdos com os objetivos de aprendizagem; a delimitação de modos teóricos para a consecução do objetivo geral de aprendizagem; e, a sustentação do problema relevante, o caso Black, para o contexto escolar, de modo a integrar conhecimentos procedentes das diferentes fontes estabelecidas (livro didático, caso, notícias, blogs, sites de internet). Em suma, essa reunião de inferências remete ao fato de que a segunda versão da UDM mantém um enfoque curricular alternativo para o conteúdo.

Na sequência, a análise da segunda versão da UDM revela a ocorrência de alterações na sexta tarefa relacionada à Seleção de Estratégias Didáticas. Conforme aponta o Quadro 4, é na SD II que os sujeitos promovem uma mudança relacionada à substituição da estratégia História e Filosofia da Ciência por CTS (Ciência Tecnologia e Sociedade). Estipula-se que uma das grandes dificuldades da utilização da estratégia História e Filosofia da Ciência está associada ao fato dela impor uma proposta que seja capaz de superar a ideia da linearidade e da acumulação de conhecimentos para o desenvolvimento científico. A análise do planejamento e dos argumentos dos licenciandos (conforme próxima seção) conduz à percepção de que o grupo não conseguiu aplicar adequadamente (em razão daquilo que foi estipulado no conjunto de tarefas da primeira versão da UDM) a estratégia em virtude dos limites de tempo e das dificuldades enfrentadas por alunos e professores em constituir uma visão adequada para o trabalho científico. O próprio grupo verificou que a estratégia CTS seria capaz substituir a proposta inicial no sentido de conferir maior coerência tanto ao planejamento quanto à ação docente. Isso se deve à percepção dos licenciandos para o fato de que essa estratégia poderia contribuir, de modo mais eficaz, para a educação científica e tecnológica dos alunos, uma vez que haveria a necessidade de ampliação dos debates em sala de aula relativos às questões políticas, econômicas, culturais, sociais, ambientais e éticas. O corolário dessas inferências remete ao fato de que não houve quaisquer alterações para o enfoque curricular alternativo no que se refere à categoria metodologia.

Por fim, quanto às estratégias de avaliação, ao contrário das outras modificações, no Quadro 4 verificam-se várias alterações nas SD I, II e III. Ocorreram problemas de decisão decorrentes da elaboração de um argumento que fugisse da generalização; da falta de parâmetros teóricos e formais, bem como da influência dos conhecimentos experienciais, oriundos da formação ambiental. Em consequência disso, as estratégias de avaliação na primeira versão da UDM foram qualificadas. A reelaboração da sétima tarefa relacionada à seleção de estratégias de avaliação manifesta aparente determinação dos licenciandos em elucidar os dilemas que foram expostos na primeira proposta avaliativa. Foram verificadas que em todas as SD propostas houve alterações direcionadas à implementação da sistematização dos conteúdos trabalhados na intenção de realizar 
contínuos feedbacks aos alunos, bem como o estímulo a sua participação em discussões acerca das temáticas abordadas.

A nova versão da UDM apresenta nas SD I, II e III a proposta de sistematização do conteúdo como forma de se manter um eixo central de atividades para a efetivação das estratégias didáticas. A intenção disso seria, aparentemente, permitir constantes retomadas aos aportes teóricos, ora trabalhados pelos docentes, ora assimilados pelos alunos. Disso decorre a dedução de que as atitudes dos alunos deixaram de ser o elemento central das estratégias avaliativas (tendência espontaneísta), conforme outrora considerado. Por esse motivo, passam a ser considerados espaços para uma avaliação contínua e processual baseada na diversidade de instrumentos, concentradas na evolução das ideias dos alunos e nas dinâmicas das aulas, bem como na ênfase de hipóteses curriculares e nas intervenções do professor. Diante disso, a segunda versão da UDM monstra a tentativa dos licenciandos em impor uma dinâmica que evidencia uma perspectiva de avaliação que transita entre do nível de formulação espontaneísta para o investigativo.

A análise geral dos enfoques curriculares do conteúdo, da metodologia e da avaliação revelam uma tendência predominantemente alternativa para o planejamento da UDM. Infere-se que a segunda versão da UDM se enquadra em uma perspectiva bastante adiantada quanto aos níveis do processo de reorganização contínua do desenvolvimento profissional propostos por Porlán e Rivero (1998).

Para finalizar e em virtude dessas considerações, descortinam-se duas conclusões. A primeira se refere ao fato de que as alterações propostas, oriundas do movimento crítico e reflexivo, na segunda versão da UDM deram conta de aproximar ainda mais as concepções dos alunos ao enfoque alternativo. E a segunda, concerne à importância desse movimento crítico e reflexivo como motivo determinante para a supressão de incoerências e promoção de articulações teórico-práticas ao longo do processo formativo estudado, conforme evidências apresentadas a seguir.

\section{O impacto da ação crítica e reflexão no replanejamento da UDM}

Posteriormente ao processo de aplicação e anteriormente ao replanejamento da segunda versão da UDM, foi promovida uma reflexão crítica por meio do GF para tratar dos problemas e das potencialidades observadas pelos licenciandos.

Diante desse contexto e na intenção de identificar e analisar os elementos determinantes para a composição do replanejamento, foram estabelecidas três categorias a priori. Essas categorias são oriundas das propostas de Porlán e Rivero (1998) para se avaliar o Enfoque Curricular adotado por professores. Além disso, seu uso é justificado em razão do Conteúdo, da Metodologia e da Avaliação comporem as pautas de discussão do GF.

Os diálogos do GF foram transcritos e analisados por meio dos procedimentos da AC. A análise manteve o interesse principal em detectar as ações pertinentes à reflexão 


\section{-Revista de Iniciação à Docência, v.6, n.2, 2021- \\ Publicação: dezembro, 2021 - ISSN 2525-4332}

crítica fundamentada. O Quadro 5 exibe as categorias analíticas determinantes na composição do replanejamento, bem como apresenta alguns extratos representativos do GF que fundamentaram sua elaboração. São reveladas evidências que justificam a reestruturação a partir da reflexão crítica sobre planejamento. Nele, o destaque foi dado em relação às motivações para ações corretivas no Enfoque Curricular do Conteúdo.

Quadro 5. Categorias analíticas referentes ao Conteúdo na composição do replanejamento e extratos obtidos junto ao GF.

\begin{tabular}{|l|l|}
\hline $\begin{array}{l}\text { Categoria } \\
\text { Conteúdo }\end{array}$ & \multicolumn{1}{c|}{ Descrição } \\
\hline $\begin{array}{l}\text { Nível de } \\
\text { formulação }\end{array}$ & $\begin{array}{l}\text { Os níveis de formulação do conteúdo levam em consideração a capacidade dos sujeitos } \\
\text { em estabelecerem movimentos reflexivos relativos à integração e adequação curricular } \\
\text { aos objetivos definidos na primeira versão do planejamento. Nessa lógica, a aproximação } \\
\text { de uma proposta pedagógica que envolva uma programação sistemática, explícita e } \\
\text { reformuladora, bem como afastada do predomínio conceitual é capaz de expor avanços } \\
\text { em relação a consolidação do enfoque investigativo. }\end{array}$ \\
\hline $\begin{array}{l}\text { Amplitude e } \\
\text { diversidade }\end{array}$ & $\begin{array}{l}\text { A consideração da amplitude e da diversidade do conteúdo podem remeter os sujeitos a } \\
\text { estados profícuos de organização autônoma da proposta metodológica adotada. Em } \\
\text { função disso, a integração de aspectos do cotidiano, do social, do científico e do } \\
\text { ideológico permitem a explicitação de avanços em relação ao conhecimento profissional } \\
\text { desejável e a consolidação de modelos didáticos individuais investigativos. }\end{array}$ \\
\hline Organização & $\begin{array}{l}\text { A organização do conteúdo demonstra reflexões de ordens práticas e teóricas. Nessa } \\
\text { perspectiva, o conhecimento metadisciplinar manifesta importante relação com os } \\
\text { âmbitos da investigação profissional na medida em que expõe referências para o } \\
\text { estabelecimento de análises críticas acerca da aplicação e reelaboração do planejamento. } \\
\text { Ademais, tal ação destaca a importância dos conteúdos procedimental e conceitual no } \\
\text { que tange a capacidade de interpretar aquilo que foi proposto e de recompor uma nova } \\
\text { versão da UDM. }\end{array}$ \\
\hline
\end{tabular}

Fonte: Elaboração própria

De modo global, as ponderações apresentadas em cada uma das categorias do Quadro 5 refletem avanços em relação ao Conteúdo. O posicionamento dos licenciandos revela a ocorrência de inconsistências e incoerências como elementos de ponderação para a constituição de um percurso possível para a elaboração da nova proposta do planejamento de ensino. Assim, entre as versões da UDM consideradas ficaram evidentes a importância dada aos aspectos da práxis investigativa.

Esse conjunto de elementos dinâmicos da metodologia parecem, ainda, estar associados a diversos termos relacionados à adequação dos conteúdos à realidade do aluno; à valorização das ideias prévias dos alunos; à proposição de atividades investigativas; e ao desenvolvimento de noções de cidadania. Tais elementos são explicitados por meio do cumprimento das tarefas de elaboração da UDM. Mais especificamente, a fundamentação para a execução de uma prática orientada pela abordagem metodológica advém da consolidação de bases teóricas e da mobilização e aplicação de metaconhecimentos pelos sujeitos. Nos termos considerados e de modo exemplar, o "Conteúdo programático da UDM" se estabelece como uma das vias de antecipação e reflexão relativa à intenção do desenvolvimento de uma prática inovadora. 


\section{-Revista de Iniciação à Docência, v.6, n.2, 2021- \\ Publicação: dezembro, 2021 - ISSN 2525-4332}

O Quadro 6 apresenta a categoria analítica que pretende representar o movimento crítico-reflexivo necessário para a realização de readequações no planejamento de ensino diante do Enfoque Curricular direcionado ao entendimento da Metodologia.

Quadro 6. Categorias analíticas referentes a Metodologia na composição do replanejamento e extratos obtidos junto ao GF.

\begin{tabular}{|l|l|}
\hline \multicolumn{1}{|c|}{$\begin{array}{c}\text { Categoria } \\
\text { Metodologia }\end{array}$} & \multicolumn{1}{|c|}{ Descrição e Extratos representativos } \\
\hline $\begin{array}{l}\text { Papel didático } \\
\text { das } \\
\text { concepções } \\
\text { dos alunos }\end{array}$ & $\begin{array}{l}\text { A intenção de se verificarem as concepções dos alunos refere-se a uma perspectiva em } \\
\text { que o professor estimula a antecipação de ideias do público referentes a determinado } \\
\text { tema do currículo. Essa dinâmica é considerada como fundamental para o } \\
\text { desenvolvimento das SD. Nesse sentido, a referida proposta pretende extrair as ideias } \\
\text { preliminares dos alunos e, a partir das dificuldades encontradas, o professor é capaz de } \\
\text { refletir criticamente e controlar suas ações nos processos de ensino e aprendizagem dos } \\
\text { conceitos científicos. À vista disso, as ideias dos alunos compreendem um referencial } \\
\text { contínuo para a investigação dos problemas que fazem parte da abordagem } \\
\text { metodológica escolhida na UDM. }\end{array}$ \\
\hline $\begin{array}{l}\text { Caracterização } \\
\text { das atividades }\end{array}$ & $\begin{array}{l}\text { As atividades investigativas pretendem estimular o interesse dos alunos. Análise das } \\
\text { concepções dos sujeitos podem especificar a adesão aos enfoques tradicional, tecnicista, } \\
\text { espontaneísta e investigativo. Destaca-se, ainda, o posicionamento crítico e reflexivo } \\
\text { diante da escolha de estratégias de ensino e do papel da metodologia adotada pelo grupo } \\
\text { em exigir o teste de hipóteses levantadas pelos alunos. }\end{array}$ \\
\hline $\begin{array}{l}\text { Interação } \\
\text { professor- } \\
\text { alunos }\end{array}$ & $\begin{array}{l}\text { A interação professor-alunos compreende o estímulo oferecido aos alunos para a } \\
\text { participação em uma investigação científica. Nesse sentido, as atividades devem ser } \\
\text { pertinentes à resolução de problemas e conformarem-se à integração entre teoria e } \\
\text { prática. O uso dessas situações problematizadoras é de fundamental importância para a } \\
\text { promoção do diálogo, da motivação para a ação dos alunos, para composição de } \\
\text { hipóteses e a resolução do problema. Assim, a geração e confronto de resultados devem } \\
\text { ser capazes de promover mudanças conceituais, procedimentais e atitudinais. }\end{array}$ \\
\hline
\end{tabular}

Fonte: Elaboração própria

Os dados apresentados manifestam as concepções dos sujeitos associadas à importância do professor como mediador das ações colaborativas e coletivas de ensino e aprendizagem, no âmbito do Ensino por Investigação (Carvalho, 2013). Os diálogos do GF evidenciam que o processo crítico e reflexivo dos sujeitos resultou em atividades que visavam o interesse dos alunos. Disso decorre a compreensão de que ao longo das declarações são manifestadas concepções alternativas com matizes do espontaneísmo.

Como ilustrado no Quadro 6, as falas dos licenciandos reforçam os dados e inferências do GF e expõem a importância de uma reflexão crítica, de caráter progressivo e dinâmico para as situações que se sucederam ao longo da prática. Sendo assim, fica evidente o vasto campo para a promoção de discussões, elaboração de propostas vinculadas à integração científica e ideológica do conhecimento escolar; à integração dos conteúdos conceitual, procedimental e atitudinal; e à ampliação de estudos relativos à variabilidade de estratégias didáticas.

Infere-se também que os licenciandos puderam participar de um processo didático-pedagógico que priorizou o desenvolvimento da ação autônoma docente. Nesse 


\section{-Revista de Iniciação à Docência, v.6, n.2, 2021- \\ Publicação: dezembro, 2021 - ISSN 2525-4332}

percurso formativo, os licenciandos realizaram uma condução didático-pedagógica singular, cuja capacidade abrangeu alcançar um enfoque curricular alternativo e reforçar o processo analítico voltado ao desenvolvimento do planejamento de ensino nos moldes das diretrizes do Ensino por Investigação.

Por fim, o movimento crítico-reflexivo dos sujeitos que se refere aos avanços e alterações nos processos de Avaliação são apresentados no Quadro 7. Conforme o resultado da análise duas versões da UDM, evidenciou-se que as estratégias avaliativas foram as que mais sofreram alterações. A análise sistemática dos dados remeteu à consideração de uma transição de Tendências Espontaneístas e para um enfoque com elementos de Tendências Alternativas.

Quadro 7. Categorias analíticas referentes a Avaliação na composição do replanejamento e seus extratos obtidos junto ao GF.

\begin{tabular}{|l|l|}
\hline \multicolumn{1}{|c|}{$\begin{array}{c}\text { Categoria } \\
\text { Finaliação }\end{array}$} & \multicolumn{1}{c|}{ Descrição e Extratos representativos } \\
\hline Conteúdo & $\begin{array}{l}\text { A finalidade da avaliação é a de regular os processos de ensino e aprendizagem por meio } \\
\text { da evolução das concepções dos alunos. Nesse sentido, há de se considerar os objetivos } \\
\text { que foram traçados e as necessidades da abordagem metodológica. }\end{array}$ \\
\hline $\begin{array}{l}\text { A metodologia escolhida pelos sujeitos impõe que a avaliação seja feita nos moldes } \\
\text { formativos. Assim, no Ensino por Investigação, o foco está nos processos de ensino e } \\
\text { aprendizagem e no diálogo permanente entre professores e alunos. Em virtude da } \\
\text { importância dada aos conteúdos conceituais, a metodologia considerada argumenta em } \\
\text { favor de atividades de aplicação do conteúdo ensinado. Ademais, essa metodologia } \\
\text { parece reforçar nos sujeitos a importância dos conteúdos procedimentais (ligados à } \\
\text { iniciativa dos alunos para analisar, por si mesmos, os resultados obtidos nos processos } \\
\text { de ensino e aprendizagem) e os conteúdos atitudinais (que corroboram aspectos da } \\
\text { formação de atitudes e valores diante da informação que foi recebida). }\end{array}$ \\
\hline Instrumentos & $\begin{array}{l}\text { A abordagem metodológica Ensino por Investigação requer instrumentos que se } \\
\text { adequem a uma proposta de avaliação formativa. Nesse sentido, devem ser } \\
\text { consideradas a evolução das concepções dos alunos e a verificação de hipóteses } \\
\text { propostas nas dinâmicas escolares. Os sujeitos consentem para a composição de } \\
\text { instrumentos formais capazes de verificar o processo de sistematização dos dados } \\
\text { levantados no contexto coletivo. }\end{array}$ \\
\hline
\end{tabular}

Fonte: Elaboração própria

Ademais, a observação das alterações em todas as SD permitiu verificar um direcionamento para a participação ativa dos alunos, no sentido de compor modos avaliativos alternativos e de sobrelevar-se diante de perspectivas pautadas em avaliações terminais baseadas em exames; na memorização de definições e exercícios abordados em uma SD; e em uma avaliação como qualificação.

Essas perspectivas de mudanças são, possivelmente, congruentes à ocorrência sistemática de ponderações pautadas na análise crítica da prática docente; no levantamento contínuo de inferências capazes de fundamentar uma perspectiva investigativa; flexibilidade para considerar as ideias dos alunos, na importância de dinâmicas coletivas ao longo das atividades; e no paralelismo entre as hipóteses curriculares envolvidas no processo. 


\section{-Revista de Iniciação à Docência, v.6, n.2, 2021- \\ Publicação: dezembro, 2021 - ISSN 2525-4332}

Em termos de seleção de instrumentos avaliativos, que tem como pano de fundo a abordagem metodológica de Ensino por Investigação, os sujeitos inicialmente experimentaram o ambiente virtual (EdModo), e isso incorreu em baixa adesão dos estudantes. As alternativas aplicadas, em razão do movimento de reflexão crítica, envolveram propostas formativas para que os alunos apresentassem as sistematizações, por meio de caderno de anotações, dos levantamentos realizados e da manutenção do procedimento formativo.

Outro apontamento relevante está na complexidade envolvida na definição do tipo de avaliação quanto ao modo individual ou coletivo. Alguns dos relatos apresentados no Quadro 7 manifestaram que a avaliação deveria ser realizada somente em grupo, sob a justificativa de que a abordagem metodológica valoriza a construção do conhecimento em grupo, porém outros relatos indicavam que a avaliação individual seria mais interessante, em função de os professores conseguirem acompanhar a evolução da aprendizagem dos estudantes de forma mais acurada e menos genérica. Nota-se como o processo de reflexão crítica sobre a ação, sobretudo de forma coletiva e mediada, resulta em um movimento essencial para melhoria do conhecimento profissional dos futuros professores.

Entretanto, cabe ressaltar que, ao longo do GF, não houve referência, por parte dos licenciandos, sobre a finalidade da avaliação também se voltar para a melhoria do próprio planejamento de ensino. Isso remete ao fato de que o grupo parece não ter se conscientizado sobre a importância global do processo avaliativo relacionado ao seu caráter tanto de avaliação das aprendizagens como do desenvolvimento progressivo dos processos de ensino.

Embora as análises empreendidas considerem o fato de que houve um deslocamento dos enfoques avaliativos das tendências mais tradicionais para outras mais alternativas, não houve por parte do grupo uma proposta específica para a composição de avaliação enquanto estratégia essencialmente investigativa. Tal consideração se justifica pela mescla de enfoques, ou seja, inicialmente predomínio de Tendências Espontaneístas para a ponderação de elementos do Enfoque curricular com viés Alternativo. Contudo, ainda há indicação de maneira vaga, na versão reelaborada da UDM, sobre como seriam as atividades na perspectiva da avaliação formativa.

De maneira global, os dados analisados revelam que o processo coletivo e mediado de reflexão crítica sobre a ação docente se mostrou bastante adequado no que se refere à: utilização da abordagem metodológica como eixo central do planejamento; organização do conteúdo do conhecimento escolar em conformidade com problemas de interesse e ideias prévias dos alunos. Os sujeitos da pesquisa mostraram perspectivas capazes de rechaçar tendências tradicionais do âmbito escolar e de consolidar propostas didático-pedagógicos caracterizadas por grande coerência e articulação interna.

Por conseguinte, resta a afirmação de que os frutos desse processo de implementação, ao menos no que tange aos elementos constituintes dos Enfoques 
Curriculares, abarcam o desenvolvimento coletivo e autônomo de estratégias de ensino e aprendizagem direcionados à investigação, além de exporem a ocorrência de rotinas flexíveis e reflexivas para a ação docente.

\section{Conclusão}

Ao longo das discussões deste artigo revela-se a ideia de que a inserção dos indivíduos em coletivos de trabalho crítico e reflexivo pode proporcionar transições de pontos de vistas práticos e teóricos para patamares inovadores.

Nesse sentido, ao longo do processo formativo relatado nesta investigação, ocorreram avanços nas concepções didático-pedagógicas dos sujeitos em virtude de a proposta formativa pactuar diante da realização de constantes acordos coletivos. Fica destacado que a proposta formativa da implementação de UDM preconiza aos licenciandos procedimentos de trabalho colaborativo mediado pelo professor formador, à proporção que os professores em formação tomam decisões após a reflexão e à análise de situações problemáticas decorrentes da prática laboral.

Outrossim, estipulam-se posicionamentos transitórios e direcionados à consolidação de tendências alternativas com referencial investigativo em relação à articulação e consolidação dos conhecimentos profissionais dos licenciandos ao replanejar o planejamento de ensino. Isso se deve ao fato de os sujeitos desta pesquisa terem se mobilizado diante de uma proposta que pretendia promover transições e evoluções de conhecimentos profissionais, além de fundamentar a constituição de um modelo didático pessoal capaz de se descolar de perspectivas tradicionais.

Nesses termos, a resposta para a questão de pesquisa anunciada no começo deste artigo se direciona à ponderação de que houve: i) substancial reorganização dos enfoques curriculares das versões da UDM, com aproximações para tendências alternativas nas perspectivas do conteúdo, da metodologia e da avaliação; ii) mobilização e integração dos diferentes conhecimentos profissionais (PORLÁN; RIVERO, 1998); progressão do conhecimento prático em razão de sua articulação com a ação docente e teorias formalizadas; melhoria da qualidade do planejamento de ensino em razão das premissas da articulação e da coerência internas assumidas em razão de uma fundamentação de uma práxis coletiva e colaborativa.

\section{Referências}

ALVES, Milena. Características, elementos e importância do planejamento didáticopedagógico: uma revisão de termos e conceitos utilizados na área de Ensino de Ciências. 2018.130 f. Dissertação (Mestrado em Química) - Instituto de Química, Universidade Estadual Paulista, Araraquara, 2018.

BABOUR, Rosaline. Grupos focais. Porto Alegre: Artmed, 2009.

BARDIN, Laurence. Análise de conteúdo. São Paulo: Edições 70, 2016. 
BEGO, Amadeu. implementação de unidades didáticas multiestratégicas na formação inicial de professores de Química. Coleção Textos FCC (Online), v. 50, p. 55-72, 2016.

BEGO, Amadeu Moura; FERRARINI, Francisco Otávio Cintra; MORALLES, Vagner Antônio. Ressignificação dos estágios curriculares supervisionados por meio da implementação de Unidades Didáticas Multiestratégicas. Educação Química en Punto de Vista, v. 5, p. 5-28, 2021.

BEGO, Amadeu Moura.; SGARBOSA, Evelin. Transitando entre o planejamento teórico e a realidade do cotidiano escolar: vivências, desafios e aprendizados. In: COLVARA, L. D., OLIVEIRA, J. B. B. (org.). Metodologias de Ensino e a Apropriação de Conhecimento pelos Alunos. 1ed. São Paulo: Cultura Acadêmica, 2016, v. 2, p. 8-32.

CAVALCANTE, Ricardo Bezerra; CALIXTO, Pedro; PINHEIRO, Marta Macedo Kerr. Análise de Conteúdo: considerações gerais, relações com a pergunta de pesquisa, possibilidades e limitações do método. Informação \& Sociedade: Estudos, João Pessoa, v. 24, n. 1, p. 1318, jan./abr. 2014.

BEGO, Thiago Moura. Conhecimentos implícitos e explícitos de professores de química em formação inicial: a implementação de unidades didáticas multiestratégicas como percurso formativo. 2017. 227 f. Dissertação (Mestrado em Química) - Instituto de Química, Universidade Estadual Paulista, Araraquara, 2017.

CARVALHO, Anna Maria Pessoa. O ensino de Ciências e a proposição de sequências de ensino investigativas. In Carvalho Anna Maria Pessoa. Ensino de ciências por investigação: condições para implementação em sala de aula (pp. 1-20). São Paulo: Cengage Learning, 2013.

FERRARINI, Francisco Otávio Cintra. Desenvolvimento do conhecimento práticoprofissional no processo de implementação de unidades didáticas multiestratégicas para o ensino de Química no contexto da formação inicial de professores. 2020. $426 \mathrm{f}$. Tese (Doutorado em Química) - Instituto de Química, Universidade Estadual Paulista, Araraquara, 2020.

GAUCHE, Ricardo. O professor e a atividade docente: questões recorrentes, soluções pendentes. In T. V. O. Gonçalves, F. C. da S. Macêdo, \& F. L. Souza, (org.). Educação em ciências e matemáticas: debates contemporâneos sobre ensino e formação de professores. 24 a . Ed. Penso Editora LTDA, cap. 07, 2015, p. 96-114.

GIBBS, Graham. Análise de dados qualitativos. Porto Alegre: Bookman/Artmed, 2009. LÜDKE, Menga; ANDRÉ, Marli. Pesquisa em educação: abordagens qualitativas. São Paulo: EPU, 1986.

Emerson Augusto de Medeiros; Giovana Carla Cardoso Amorim. Análise textual discursiva: dispositivo analítico de dados qualitativos para a pesquisa em educação. Laplage em Revista, v.3, n.3, p. 247-260, 2017

PACCA, Jesuína Lopes de Almeida.; SCARINCI, Anne Louise. O truncamento da sequência pedagógica do professor de física. Investigações em Ensino de Ciências, v. 18, n. 3, p. 681696, 2013.

PORLÁN, Rafael Ariza; RIVERO, Ana Garcia. El conocimiento de los profesores. Sevilla: 
Diada. 1998.

SÁ, Luciana Passos; FRANCISCO, Cristiane Andretta; QUEIROZ, Salete Linhares. Estudos de caso em química. Química Nova, v.30, n.3, 731-739, 2007.

SANCHEZ, Blanco; VALCÁRCEL, Pérez. Diseño de unidades didácticas en el área de Ciencias Experimentales. Enseñanza de las Ciencias, v.11, n.1, 33-44, 1993. Disponível em: https://raco.cat/index.php/Ensenanza/article/view/39774. Acesso em: 27 out. 2021.

SANCHEZ, Blanco; VALCÁRCEL, Pérez. Qué tienen en cuenta los professores cuando seleccionam el contenido de enseñanza? Cambios y dificultades tras un programa de formación. Enseñanza de las Ciências, v.18, n.3, 423-437, 2000. Disponível em: https://raco.cat/index.php/Ensenanza/article/view/21692. Acesso em: 27 out. 2021.

YIN, Robert. Estudo de Caso: planejamento e métodos. 2. ed. Porto alegre: Bookman, 2001. 